\title{
Trabajo Social y Justicia Juvenil: contradicciones y disputas presentes en el contexto actual
}

\author{
Karina De Bella ${ }^{1}$ \\ https://orcid.org/0000-0002-4469-8143 \\ ${ }^{1}$ Universidad Nacional de Rosario, Facultad de Ciencia Política y RRII, Centro de Investigación en Campos de Intervención del Trabajo \\ Social, Rosario, Sta. Fe, Argentina
}

Trabajo Social y Justicia Juvenil: contradicciones y disputas presentes en el contexto actual

Resumen: El presente artículo aborda la problemática de los derechos humanos de los/las jóvenes-adolescentes "en situación de conflicto con la ley" en relación con las reformas que se proponen para su tratamiento en un contexto de neoconservadurismo. Pensar en las luchas por los derechos humanos y ubicar las estrategias del Trabajo Social en los espacios institucionales sociojurídicos habilita el debate profesional y fundamenta las acciones políticas desplegadas para la defensa de los derechos, en particular, de jóvenes-adolescentes. En este marco, la instalación mediática de la problemática y la aparición de la reforma legal como único camino resultan un abordaje unilateral y sesgan la compresión del campo de la justicia juvenil. Sostenemos que existe en la justicia juvenil una seducción por los derechos procesales, más no por la integralidad de los derechos humanos, en particular de jóvenes-adolescentes. Se han producido, sin embargo, una serie de intentos de reforma de este estado de cuestión, los trabajadores sociales hemos participado generando una rica experiencia.

Palabras clave: Justicia juvenil. Trabajo Social. Derechos. Intervención.

\section{Serviço Social e Justiça Juvenil: contradições e disputas presentes no contexto atual}

Resumo: Este artigo aborda os direitos humanos de jovens adolescentes "em conflito com a lei" em relação às reformas propostas para o seu tratamento em um contexto de neoconservadorismo. Pensar nas lutas pelos direitos humanos e localizar estratégias de assistência social em espaços institucionais sócio-legais possibilita o debate profissional e embasa as ações políticas implantadas para defender os direitos, em particular, dos jovens-adolescentes. Nesse contexto, a instalação do problema pela mídia e o surgimento da reforma legal como único caminho são uma abordagem unilateral e distorcem o entendimento do campo da justiça juvenil. Defendemos que há uma sedução na justiça juvenil pelos direitos processuais, mas não pela abrangência dos direitos humanos, particularmente dos jovens-adolescentes. No entanto, houve uma série de tentativas de reformar esse estado de coisas, assistentes sociais participaram da geração de uma rica experiência.

Palavras-chave: Justiça juvenil. Trabalho social. Direitos. Intervenção.

\section{Social Work and Juvenile Justice: contradictions and disputes present in the current context}

Abstract: This article addresses the human rights problems of young adolescents "in conflict with the law" in relation to the reforms proposed for their treatment in a context of neoconservatism. Thinking about the struggles for human rights and locating Social Work strategies in socio-legal institutional spaces enables professional debate and bases the political actions deployed to defend the rights, in particular, of young people-adolescents. In this framework, the media installation of the problem and the appearance of the legal reform as the only way are a unilateral approach and skew the understanding of the field of juvenile justice. We maintain that there is a seduction in juvenile justice for procedural rights, but not for the comprehensiveness of human rights, particularly of young people-adolescents. However, there have been a series of attempts to reform this state of affairs, social workers have participated generating a rich experience. Keywords: Juvenile justice. Social work. Rights. Intervention.

Recibido en 03.10.2019. Aprobado en 11.02.2020. Revisado em 26.02.2020

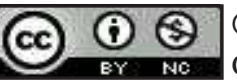

(C) El(Los) Autor(es). 2020 Acceso Abierto Esta obra está licenciada bajo los términos de la Licencia Creative Commons Atribución-NoComercial 4.0 Internacional (https://creativecommons.org/licenses/by-nc/4.0/deed.es), que permite copiar, distribuir y reproducir en cualquier medio, así como también adaptar, transformar y crear a partir de este material, desde que para fines no comerciales, y que usted fornezca el crédito debido a los autores y a la fuente, insiera un enlace para la Licencia Creative Commons e indique si fueron hechas alteraciones. 


\section{Introducción}

Partimos de considerar que la base del análisis institucional, específicamente en los espacios sociojurídicos, es el análisis de las contradicciones, integrándolas al campo específico, en nuestro caso, la justicia juvenil. Para ello, partimos de la concepción materialista dialéctica, entendiendo que, en la producción social de su existencia, los seres humanos establecen relaciones entre sí, relaciones sociales necesarias, independientemente de su voluntad, siendo lo fundamental las relaciones de producción entre los hombres y mujeres y la naturaleza. La historización social permite comprender las diferentes conformaciones de la estructura social y la superestructura jurídica, religiosa, militar, etc. como elementos fundamentales para sostener las relaciones diferenciadas de la base social. Por lo tanto, la función de la superestructura es de legitimación-legalización. En las sociedades divididas en clases antagónicas, se crea un aparato burocrático-administrativo, el Estado, con el cual todas las instituciones tienen relación.

En la superestructura se dan contradicciones, por lo tanto, en las instituciones y organizaciones, este movimiento actúa sobre la estructura. Esta complejidad y este carácter contradictorio de las instituciones no aparece en general en los análisis de los institucionalistas, que consideran que éstas son negativas "per se". No se analiza cómo, a pesar de que hay ideas instituidas dominantes, también hay ideas instituidas que están expresando a lo dominado, y muchas veces lo dominante se abre paso aboliendo aspectos positivos anteriormente instituidos. En un análisis dialéctico, pretendemos observar el campo de la justicia juvenil en relación con el Estado y también en relación con su carácter específico. Pretendemos, además, analizar el Trabajo Social en relación con los mandatos institucionales, y la producción de experiencias colectivas de organización y lucha, en disputa con tendencias reformistas individualistas/liberales. Incluimos el concepto de contradicción y el análisis de la historia (qué es lo instituido, lo nuevo, los indicios transformaciones en el campo). El objetivo es analizar sus múltiples relaciones en términos de contradicciones, de unidad y de lucha de contrarios, donde las relaciones son siempre recíprocas.

\section{Justicia juvenil: un campo en disputa}

Las formas de los Estados burgueses son extraordinariamente diversas, en su expresión de democracia burguesa, habilitan un juego limitado entre las clases sociales antagónicas, apareciendo el Estado de derecho como su formulación más acabada, por lo menos en Argentina. En este sentido, no consideramos el Estado como un ente abstracto ubicado por encima de la sociedad, por el contrario, nos preguntamos ¿Estado de derecho para quiénes? Es en la búsqueda de respuestas a este interrogante que pensamos el Estado como un espacio contradictorio, en permanente tensión y disputa. En las sociedades divididas en clases, frente a esta contradicción y en existencia de antagonismos irreconciliables, expresados justamente en la lucha de clases por conquistar el poder económico y político:

se hace necesario un poder situado aparentemente por encima de la sociedad y llamado a amortiguar el choque, a mantenerlo en los límites del "orden". Y ese poder nacido de la sociedad, pero que se pone por encima de ella y se divorcia de ella más y más, es el Estado. (Engels como se cita en Lenin, 1985, p. 13).

Es a partir de este entendimiento que ubicamos el campo de la justicia juvenil, como un campo de disputa y de contradicciones entre las posiciones punitivitas del Estado y las posiciones convencionalistas ${ }^{1}$, que propugnan otros abordajes con sustento en la justicia restaurativa, el paternalismo jurídico, etc. Disputas, claro está, dentro del marco del Estado de derecho. Las contradicciones entre pena/castigo y protección/reintegración se expresan en los proyectos de reformas legislativas. Existen en el campo los teóricos liberacionistas, quienes argumentan que la supuesta inferioridad de la infancia tiene origen en los prejuicios de los grupos dominantes. Es necesario entonces liberar a los/las niños/as, al igual que se ha hecho con otros colectivos, y esta emancipación sólo podrá realizarse a través de permitirles la toma de decisiones autónomas, de dejarles elegir libremente sus proyectos personales. De esta manera, muchos autores creen que la niñez es un fenómeno que tiende a desaparecer en la medida en que se van eliminando las estructuras que la sostienen y que impiden el ejercicio completo de la autonomía, de modo que la historia de la infancia tendrá como culminación la desaparición del niño/de la niña como categoría social (González Contró, 2006, pp. 102-103). La tesis liberacionista postula la no intervención del Estado, y en función de ello, en muchas oportunidades, se desprotege. La contradicción principal es entonces cómo se concibe al sujeto, en nuestro caso, al sujeto de la intervención social. Desde esta concepción, el sujeto liberal es autónomo y libre en sus acciones, por lo tanto, no hay especialidad en el "tratamiento" ${ }^{\circ}$ abordaje de jóvenes en conflicto con la ley. El problema es normativo, si no cumplís o trasgredís la ley (codificada en las 
normativas penales), las consecuencias punitivas son obvias y no se prestan a discusión. Esta idea de la desaparición del niño o niña (nosotros agregamos de los/las jóvenes-adolescentes) como categoría social es fundamental para leer en profundidad las tendencias presentes en las reformas en juego. Si no hay niños/as, jóvenes-adolescentes, con sus particularidades, singularidades y, principalmente, con diferencias de clase, se propende a tratarlos con los ordenamientos legales generales o para los mayores de edad (o régimen de adultos) resultando esto en reformas normativas que aparecen como "amalgamas" o "anexos" del régimen de adultos. Esto se fundamenta, especialmente, en la necesidad de la penalización y el castigo.

En cambio, otras posiciones más vinculadas a lo convencional o a la centralidad de las categorías de niños/as, jóvenes-adolescentes, entienden que la respuesta estatal tiene que ser diferenciada y sustentada en otros tipos de abordajes, donde la penalidad sea eventual, es decir, se evalúa si es o no necesaria, se evalúa que el objetivo sea la reintegración social y que se tienda a procesos restaurativos y de protección. Lo que está en juego en esta posición es claramente una concepción distinta del sujeto, que ya no es entendido en términos del sujeto liberal, sino como un sujeto determinado por una complejísima trama de vínculos y relaciones sociales, y que por lo tanto debe ser abordado en las distintas tramas vinculares que son el escenario de su experiencia: el grupo, el vínculo, las instituciones sociales. Dice Pichon-Rivière (1985):

entiendo al hombre como configurándose en una actividad transformadora, en una relación dialéctica, mutuamente modificante con el mundo, que se da siempre a su experiencia como mundo social, es decir entretejido de vínculos y relaciones sociales. Nada hay en él que no sea la resultante de la interacción entre individuos, grupos y clases.

Desde esta posición dialéctica es que retomamos la expresión “jóvenes en situación de conflicto con la ley", sólo para ubicar que se trata de jóvenes-adolescentes que ingresan a los sistemas judiciales porque recae sobre ellos un reproche penal estatal que los sitúa en la experiencia judicial. Por tanto, no se reduce su concepción a esta nominación, sino que, desde lo que planteamos como concepción de sujeto, se los/las entiende en su complejidad, y se abre camino a la problematización, entre otras cosas, de las teorías del delito, superando la visión simplista del delito entendido únicamente como quebrantamiento de las normas codificadas. ${ }^{3}$ Es decir, el castigo como simple merecimiento no tendría lugar. En todo caso habría que repensar la sanción en jóvenes-adolescentes en sentido amplio, incluyendo la noción de responsabilidad, no sólo jurídica o penal. Es decir, resignificar la sanción en un proceso que permita algunas modificaciones en la historia personal y colectiva de los/las jóvenes-adolescentes. En este sentido, sostenemos la necesidad de las intervenciones interdisciplinarias en dicho proceso judicial y resignificamos el Trabajo Social en el campo de la justicia juvenil, sustentando las siguientes hipótesis:

- Las intervenciones del Trabajo Social en el campo de la justicia juvenil constituyen "ofrecimientos de posibilidades" para los/las jóvenes en situación de conflicto con la ley, orientados a movilizar, reorientar subjetiva y objetivamente sus trayectorias de vida, y favorecer procesos tendientes a la reintegración social.

- El Trabajo Social constituye un dispositivo estratégico en el campo de la justicia juvenil para producir procesos de subjetivación en base a las singularidades del/de la joven.

La perspectiva conceptual de pensar la intervención del Trabajo Social, particularmente en este campo, como "ofrecimiento de posibilidades", es producto de significar desde otros marcos teóricos epistemológicos la idea de tutela estatal, en términos de cuidado y protección, recordando que la Convención de los Derechos de Niños, Niñas y Adolescentes y otros instrumentos legales plantean claramente la idea de un juez/una jueza especializado/a en la materia, que debe tomar disposiciones con sentido de proporcionalidad (relación acto y circunstancias del/ de la joven), de acuerdo con la quinta Regla de Beijing ${ }^{5}$ y los ordenamientos legislativos vigentes. ${ }^{6}$

La intervención en este campo de los/las trabajadores/as sociales insertos/as en espacios sociojurídicos está directamente asociada al diseño, formulación, proposición, seguimiento y evaluación de las medidas de las que son objeto/sujeto de intervención los/las jóvenes imputados/as o declarados/as autores/as responsables. En esta intervención profesional, que tiene como eje principal el proceso penal en curso, ya que define la situación procesal del/de la joven, se despliegan y organizan estrategias de trabajo. Para arribar a las mismas, el trabajador social recurre a las políticas públicas ofertadas por el Estado para este sector poblacional - en la provincia de Santa Fe, a través de la Dirección Provincial de Justicia Penal Juvenil (DPJPJ) - y a otros recursos estatales. Reúne el complejo legal normativo y la realidad social del/de la joven. Aporta elementos para comprenderlo como sujeto en "situación de conflicto con la ley", teniendo en cuenta las circunstancias personales, en las que 
atraviesa cambios subjetivos propios de la adolescencia, su historia familiar-social en relación con el contexto y el territorio donde se desarrolla su vida cotidiana. Todo ello requiere de marcos conceptuales, reflexiones, definiciones técnico-operativas y propositivas, y el uso de instrumentos propios de la intervención profesional. Estas construcciones, particulares y singulares para cada joven, se materializan en informes que se elevan al juez/a la jueza, que, como dijimos, debe tomar medidas proporcionales. Consideramos, por tanto, que la tarea del trabajador social en este campo es de suma importancia por su proximidad con el/la joven, por el conocimiento de su cotidianeidad, por la escucha entrenada que le permite crear un espacio propositivo y reflexivo de posible incidencia en la trayectoria de su vida, que es la materia prima de su trabajo A través del abordaje desarrollado por el trabajador social, se procura un proceso de intervención específico, que opera a través de las medidas que el juez/la jueza dispone. En este "tratamiento" aparece la cuestión de las medidas dispuestas: de cuáles valerse, teniendo en cuenta la determinación de las problemáticas presentes, las respuestas de los dispositivos de las políticas públicas para abordarlas, las posibilidades objetivas y subjetivas del/de la joven para resituarse en su historia personal. Por ello, si partimos desde este derecho (tutela, protección) que asiste al/a la joven, la cuestión de las medidas cobra otro sentido, podríamos decir que las mismas pueden constituir "ofrecimientos de posibilidades", y aquí es donde radica, para nosotros, la importancia de las intervenciones del Trabajo Social: tornar posible algún desplazamiento, hacer alguna apertura de perspectiva, esbozar nuevos puntos de vista en un proceso judicial con el/la joven.

\section{[...] cuando planteamos la idea de "ofrecimientos de}

\section{posibilidades", nos estamos} refiriendo a producciones nuevas, resultado de ciertas

al sujeto en su faz activa, como un sujeto sociodeseante, producto y productor de sus condiciones de existencia, y no como un objeto maleable. transformaciones que incluyen

En este punto encontramos un debate contradictorio sobre diversas maneras de comprender la intervención del Trabajo Social y el trabajo interdisciplinario. Desde la corriente ideológica basada principalmente en los fundamentos de García Méndez (1994), se entiende que la intervención del Trabajo Social o de equipos interdisciplinarios incurre, en ocasiones, en arbitrariedades sobre lo que se considera derecho penal de acto y derecho penal de autor. ${ }^{7}$ Este tipo de intervenciones contaminan un proceso que es estrictamente penal y generan situaciones de tipo tutelaristas y represivas, que no garantizan, paradójicamente, el debido proceso. Asimismo, estas intervenciones entienden la disposición de medidas tutelares en términos de sanciones y como restricción de derechos. Siguiendo esta línea, podría decirse que, de alguna manera, la existencia de las intervenciones interdisciplinarias y del Trabajo Social, implicarían la reproducción y perpetuidad de la doctrina de la situación irregular y el juez/la jueza sigue siendo visualizado/a como pater familias.

Desde nuestra perspectiva, entendemos que las medidas dispuestas posibilitan la iniciación de un proceso de intervención con el/la joven-adolescente en situación de conflicto con la ley, en un camino que lo/la pueda resituar, que le permita repensar su historia y trazar, dentro de sus condiciones subjetivas y objetivas, otra posible trayectoria de vida. De este modo, la perspectiva de la reintegración social cobra fuerza y sentido y no así la sanción y/o el castigo. Ésta es una cuestión fundamental, porque la primera visión que expusimos predomina como discurso ideológico y, podríamos decir, opera como un paradigma de obturación, en tanto ve que toda acción dispensada desde el ámbito judicial (sociojurídico) hacia los/las jóvenes-adolescentes es, como mencionamos, una intromisión, una restricción de derechos y una sanción.

Estas configuraciones ideológicas entran en disputa y se juegan en las prácticas institucionales y discursivas, plasmándose en los proyectos de reforma. Volveremos sobre este punto.

Continuando con el planteo de la intervención como "ofrecimiento de posibilidades", desarrollamos una particular concepción del sujeto de la intervención, pero es necesario particularizar el momento de la vida de los/las jóvenes. Es por ello por lo que nos referimos a "jóvenes-adolescentes", volviéndose esto central, a pesar de que la categoría de adolescencia ha sido denostada. Stella Maris Firpo (2013, 2014, p. 27) plantea: "lo que fundamenta el pensar una especificidad es considerar a la adolescencia como un momento que hace a la constitución subjetiva, y no en el sentido cronológico". Y agrega que la definición de adolescencia carece de aceptación unívoca, pero las definiciones coinciden en señalar que es un momento transicional en el que se ocupa un lugar ambiguo entre el ya no de la infancia y el aún no de la vida adulta. Se transita una zona de frontera plena de conflictos y a su vez de múltiples potencialidades, en la que los adolescentes 
necesitan de un otro que acompañe, legitime, habilite y los ayude a ingresar en las responsabilidades. Se produce algo nuevo, que no es igual a lo anterior. Silvia Bleichmar (2008) plantea que el primer derecho que tiene el niño/la niña (agregamos los/las jóvenes-adolescentes) es a una asimetría protectora, que no es la simetría con el/la adulto/a. La potencia de esta conceptualización radica para nosotros en la idea de la necesidad de que un otro/una otra acompañe, legitime, habilite y los/las ayude a ingresar en las responsabilidades. Es aquí donde reside una de las claves para pensar en el trabajo profesional disciplinar e interdisciplinar. Sobre todo, porque hablamos de jóvenes-adolescentes duramente azotados por condiciones de vida muy adversas, pertenecientes en su mayoría a la clase trabajadora.

Consideramos entonces que, cuando planteamos la idea de "ofrecimientos de posibilidades", nos estamos refiriendo a producciones nuevas, resultado de ciertas transformaciones que incluyen al sujeto en su faz activa, como un sujeto sociodeseante, producto y productor de sus condiciones de existencia, y no como un objeto maleable. Podríamos sostener, siguiendo a Osvaldo Marcón (2011), la idea de la construcción de medidas con sentido de corresponsabilidad, es decir, de responsabilidades compartidas, no sólo responsabilidades del/de la joven-adolescente, quien debe comportarse según ciertas normas y asumir responsabilidades para proyectarse hacia el futuro, sino también de los agentes institucionales, que deben generar estímulos contextuales promotores de cambios productivos en la realidad de estos jóvenes. El autor citado sostiene que el vector de análisis de la intervención debe constituirse en los procesos de responsabilización del sujeto, sin excluir el contenido de asistencia que toda medida supone, ni el inevitable contenido de vigilancia que lo judicial importa. Pero agrega que es necesario resignificar estos conceptos hacia la idea de que el/la joven debe responder por sus actos, teniendo en cuenta lo que él/ella puede. No se trata de esperar de manera ingenua una respuesta, sin modificar elementos del contexto, sino que es necesario rediscutir esta relación, exhibiendo cambios desde el lugar desde el que se impone la medida, cambios que hagan suponer la asunción de responsabilidades desde ambas partes.

Asimismo, cuando hablamos de "ofrecimiento de posibilidades", no lo estamos haciendo en términos de evaluar éxito o fracaso, sino de atender a movimientos posibles, reorientaciones, etcétera. Es conveniente advertir que la pretensión, en todo caso, sería pensar que:

la intervención sobre situaciones se centra en características y funcionamientos, en problemáticas que es preciso desplegar, en interrogaciones que importa descifrar. No para resolverlas, como para dejarlas señaladas y contribuir a su elaboración junto con el usuario. No para obrar para él, sino con él. No para salvarlo, sino para acompañarlo con pasión y, a la vez, con distancia. No se trata entonces de imponerle que sea responsable sino de proponerle que se las arregle para responsabilizarse de lo que pueda, en el marco de imposiciones objetivas, de límites socio políticos dados, en el seno de una formación económico-social en la que no ha elegido vivir, pero en la que debe vivir. Responsable de alguna parte de su destino, de algún segmento de su vida individual y colectiva (Karsz, 2007, p. 177).

Resulta imperioso señalar que este proceso de reestructuración de la materia prima, en este campo particular, sí puede incidir sobre decisiones judiciales. Siguiendo al autor recién mencionado, entendemos que las intervenciones no son homogéneas en su totalidad. No obstante, las intervenciones sociales tienen forzosamente una mira normativa y normalizadora. Karsz (2007) se pregunta: ¿qué hacen los trabajadores sociales?, y afirma que la respuesta se encuentra en la dialéctica, o sea, en las tensiones y contradicciones sin las cuales el Trabajo Social simplemente deja de existir.

Asimismo, resulta necesario advertir sobre otra cuestión que nos llevaría a caer en "aproximaciones subjetivistas o relativistas de los procesos sociales" (Tonet, 2010) si afirmáramos "la necesidad de recuperar los discursos de las personas involucradas, de basar la intervención profesional en sus deseos y expectativas, negando toda relación entre el ser social y tendencias sociales mayores" (Mallardi, 2013, p. 15). Ésta no es nuestra perspectiva.

Retomando la segunda hipótesis que planteáramos y en función de pensar los principios y objetivos que se establecen para la justicia juvenil, las funciones que fueron instituidas para los trabajadores sociales, los referenciales teóricos presentes en el ejercicio profesional (la concepción de sujeto y sociedad, entre otras), las prácticas desplegadas en el proceso de intervención desarrolladas con el/la joven-adolescente, la relación actocircunstancia, etc., es que nos detenemos a analizar el Trabajo Social en términos de dispositivo. Tomando a Michel Foucault, Giorgio Agamben y Saúl Karsz, entendemos al dispositivo como una red, en términos de su función de generar procesos de subjetivación/desubjetivación y en cuanto a su valor estratégico. ${ }^{8}$ Siguiendo esta conceptualización, consideramos que al hablar de dispositivo, específicamente en este campo, los elementos a considerar son los siguientes: las definiciones en torno al modo en que se concibe la justicia juvenil y las contradicciones entre reintegración social y penalización; las definiciones en torno a la manera como se concibe el delito y, por ende, la particular forma de establecer relaciones entre los sujetos y las relaciones sociales más 
amplias; las políticas sociales y su imbricación en esta problemática, es decir, la política pública como resorte necesario y objetivo de esos ofrecimientos, en el marco de las responsabilidades del Estado. Forman parte también de este dispositivo lo dicho acerca de las incumbencias del Trabajo Social; su mirada en permanente comunicación con el/la joven, su familia y/o terceros/as responsables, a la vez que con los anclajes institucionales; y la interdisciplina que se juega entre el saber jurídico y el saber social, entendiendo que el saber jurídico forma parte de las ciencias sociales en general.

\section{Trabajo Social: ¿la intervención judicial como ofrecimiento de posibilidades?}

La pregunta invita a la reflexión e indagación sobre el para qué y el cómo de las intervenciones judiciales, sus posibilidades, límites y potencialidades. Dichas intervenciones conllevan conceptualizaciones teóricas, ideas, prejuicios y sentires. Lamentablemente, escasamente explicitadas. Se trata, por lo tanto, de pensar la intervención judicial como un proceso complejo que incide en las trayectorias de vida de quienes son objeto del reproche penal. Por ello, es indispensable reflexionar sobre el para qué de nuestra intervención y estar atentos a las múltiples consecuencias de nuestro pensar-accionar. Ser conscientes del juego de nuestra propia subjetividad y de la posición ética y política al momento de la intervención, mezclada entre incumbencias y funciones, las más de las veces instituidas en sendas reglamentaciones, normativas, etc. En algunos casos las intervenciones funcionan como corset, generando impotencia, y en otros, dejan lugar a posiciones cómodas funcionales a la reproducción social, en ocasiones, revestidas con discursos de un sociologismo que opera como enunciado políticamente correcto. Cabe preguntarse, entonces, qué sucede con el sujeto de la intervención. El desafío es la articulación de un conjunto de elementos que hacen a la intervención judicial, y la indagación sobre las peripecias de dicha intervención. En este camino, a sabiendas del peso histórico que tiene lo penal, tanto en lo discursivo como en su materialidad, expresado en sus tribunales, códigos, etc., nos permitimos afirmar la pregunta inicial.

Desde nuestra posición, se estima que el proceso penal no debe ser sólo un mecanismo de persecución y sanción penal, sino un mecanismo de solución de conflictos, para lo cual se hace necesario abrir paso, en reemplazo de la pena, a soluciones restaurativas, en ciertas circunstancias y previa evaluación de criterios psicosociales de los intervinientes. Las intervenciones disciplinarias e interdisciplinarias entran en juego, debiendo ser capaces de incorporar otros saberes y prácticas específicos de los sujetos y comunidades. Diagnósticos, informes, pericias, criterios son puestos en jaque en nuevas redefiniciones. Aquí cobra sentido cómo opere y se construya lo que nosotros denominamos ofrecimiento de posibilidades, donde no sólo está el sujeto adolescente, sino la relación compleja entre los diferentes actores del proceso, y la incidencia del Trabajo Social en las decisiones judiciales sobre el futuro de los/las jóvenes-adolescentes.

\section{Conclusiones finales}

Nos encontramos en un momento sociohistórico de ascenso de gobiernos neoconservadores en la región. El embate contra las conquistas de los derechos en todos los ámbitos, nos encuentra en procesos de reorganización y de nuevas luchas por defender lo conquistado y continuar ampliando el espectro de derechos no concretados aún. El campo de la justicia juvenil no está exento, se procuran instalar modificaciones que sobrevaloran las herramientas legales sobre las discusiones más amplias que implican debatir, ni más ni menos, el futuro de los/ las jóvenes-adolescentes. La tendencia a la instalación de regímenes penales juveniles sigue predominando, a sabiendas de las consecuencias que han traído: mayores niveles de prisionización, altas tasas de encarcelamiento, ingreso a temprana edad a procesos judiciales, etc. Se denostan los abordajes complejos y la necesidad de políticas sólidas con recursos suficientes, y se ofrece la penalización como fórmula mágica y economicista ("anexar", "amalgamar" los regímenes de adultos), borrando el carácter ontológico de la categoría niños/as, jóvenes-adolescentes y la necesidad de una respuesta estatal diferenciada, para lo cual se necesita del trabajo interdisciplinario y de presupuestos realistas. La lucha por la defensa de la especialidad en el campo de la justicia juvenil toma cuerpo y sentido en tanto lucha democrática por los derechos humanos. Allí radica el sentido político de tomar partido en su resguardo férreo. Decíamos que en muchas ocasiones no se analiza cómo, a pesar de que hay ideas instituidas dominantes, también hay ideas instituidas que están expresando a lo dominado, y muchas veces lo dominante se abre paso aboliendo aspectos positivos anteriormente instituidos. En la provincia de Santa Fe (Argentina), nos hemos encontrado concretamente con proyectos de reforma que intentaron "adultizar" la respuesta estatal, mediante cambios normativos que volvieron prescindible la intervención específica del Trabajo Social y, en consecuencia, todo tipo de trabajo interdisciplinario e interinstitucional. Por 
ello, sostenemos que es imprescindible estudiar el carácter de los proyectos de reforma, porque si bien el debate por la fijación de la edad de punibilidad es muy importante, no debe eclipsar que lo principal es la no penalización, y, en su caso, mantener la eventualidad, pensar en medidas alternativas a la privación de libertad; en síntesis, pensar al sujeto en su realidad social concreta y construir con él/ella “ofrecimientos de posibilidades", bajo los principios convencionales. No hay que olvidar que mayoritariamente los/las jóvenes-adolescentes que ingresan el sistema judicial son hijos/as de la clase trabajadora (y de los/las desocupados/as), con duras vivencias de históricos avasallamientos a sus derechos más elementales.

Expresábamos que la historización social permite comprender las diferentes conformaciones de la estructura social y la superestructura jurídica, religiosa, militar, etc. como elemento fundamental para sostener las relaciones diferenciadas de la base social.

Se nos presentó al sujeto liberal y a sus derechos individuales como la máxima fórmula a sustentar en las reformas planteadas. Los trabajadores sociales hemos estudiado el carácter y el sentido político de las mismas, y nos dimos un duro y arduo trabajo desnaturalizando esta versión de lo social, basada en el individualismo a ultranza. La experiencia significó abrir un proceso de debate y formación, realizar acciones políticas con representación sindical a través del Sindicato de Trabajadores Judiciales, entre otras. Apostar a pensar cómo y para qué trabajar con los sujetos judicializados permite hacernos cargo de las funciones e incumbencias establecidas, rediscutirlas y desembarazarnos de los lugares estigmatizantes, que nos ubican siempre en el lugar del control y la reproducción social. Trabajar en el Poder Judicial parece ser uno de esos lugares sacrílegos y, podríamos decir sin temor a equivocarnos, vergonzantes. Ahora bien, como dice mi colega Marcón: ¿qué instituciones están por fuera de las dosis del control social?

Explorar desde otras perspectivas nuestras propias intervenciones, en el marco de la sociedad en la que se despliegan, propicia la lucha por abrir debates y por conjugar el contenido de control que toda medida judicial reporta con otros sentidos, en imbricación con los derechos colectivos. Allí inscribimos nuestra lucha, de la que participamos activamente, para repensarnos y ubicarnos en otros lugares, no sólo los asignados o a designar como mandatos inquebrantables. Lo colectivo fructifica y airea lo instituido, para construir sobre nuevas bases. La posibilidad siempre está, se trata de tomarla, analizarla, hacer alianzas políticas, buscar representación sindical. El neoliberalismo se instala ideológica y culturalmente afirmando que éste es el "único mundo posible" y, en particular, en materia de justicia juvenil, se expresó como "instauración de los derechos procesales", como mencionáramos en el presente escrito, generando una amplia seducción en sectores denominados progresistas, los cuales curiosamente bregan por la instalación de regímenes penales juveniles e instan a bajar la edad de punibilidad a los 14 años. ${ }^{9}$ Nuestra experiencia significó que la lucha, la organización, la representación sindical continúan siendo herramientas indispensables para contrarrestar la idea hegemónica del "único mundo posible". Recuerdo que, al inicio de los debates, muchos/as compañeros/as de trabajo nos decían "pero ustedes no van a perder el trabajo, las pasaran a otros fueros", expresiones inmediatistas e individualistas, frente a las cuales nuestra respuesta fue "está en juego lo que va a pasar con los/las jóvenes-adolescentes de nuestra provincia durante muchos años y lo que se avecina no es bueno". Es decir, que los/las trabajadores/as sociales tuvimos mucho que aprender y desafiar en este proceso, logrando que la iniciativa de reforma netamente penalizante no lograra consenso y no se pudiera presentar en la Cámara de Diputados de la provincia de Santa Fe. Otro proyecto gubernamental fue presentado, incluyendo la creación de una dirección interdisciplinaria y la incorporación de los principios de la justicia restaurativa. Logros parciales, es cierto, pero que significaron posicionarnos política y disciplinariamente como actores imprescindibles frente a nuevos intentos de reforma. Este proceso nos permitió jugar, en lo que concierne al Trabajo Social, sobre algunos de sus desafíos para la concreción de un perfil profesional crítico, teóricamente consistente, comprometido con los valores humanos en general y con competencia técnico-política.

\section{Referencias}

Bleichmar, S. (2008). Violencia social-violencia escolar: De la puesta de límites a la construcción de legalidades. Buenos Aires: Noveduc. (Conjunciones, TOMO 13).

De Bella, K. (2016). Justicia Juvenil y Trabajo Social: La incidencia de las intervenciones profesionales del Trabajo Social en las trayectorias de los jóvenes en situación de conflicto con la ley. (Tesis doctoral). Recuperado de https://rephip.unr.edu.ar/bitstream/ handle/2133/7895/Tesis\%20Karina\%20De\%20Bella\%20final\%202016.pdf.

Firpo, S.M. (2013, 2014). La construcción social y subjetiva de la infancia y adolescencia. Buenos Aires: Letra Viva.

García Fanlo, L. (2011, marzo). ¿Qué es un dispositivo?: Foucault, Deleuze, Agamben. Aparte Rei, España, 74, 1-8. Recuperado de http://serbal.pntic.mec.es/ cmunoz11/fanlo74.pdf 
González Contró, M. (2006, octubre). Paternalismo jurídico y derechos del niño. Isonomía, México, 25. 101-135. Recuperado de http:/ /www.scielo.org.mx/pdf/is/n25/n25a6.pdf

Karsz, S. (2007). Problematizar el Trabajo Social: definición, figuras, clínica. Barcelona: Gedisa.

Lenin, V. (1985). El Estado y la revolución. Buenos Aires: Alianza Editorial.

Mallardi, M. (2013). Cuestión social y situaciones problemáticas: aportes a los procesos de intervención en Trabajo Social. Cátedra

Paralela, Rosario, 9, 14-30. Recuperado de https://rephip.unr.edu.ar/bitstream/handle/2133/5020/

Mallardi.pdf?sequence $=3 \&$ is Allowed $=\mathrm{y}$

Marcón, O. (2011). Jóvenes en situación de conflicto con la ley penal: ¿cómo relatan sus historias? Análisis y prospectivas desde la Justicia Juvenil Restaurativa. Buenos Aires: Teseo.

Pichon-Rivière, E. (1985, agosto). Fundamentos de una Psicología Social. En Encuentro Internacional de Psicodrama y Psicoterapia de Grupo, Buenos Aires.

Zaffaroni, E. (1995). Manual de Derecho Penal: Parte general. Buenos Aires: Ediciones Ediar.

\section{Notas}

1 Se hace alusión a la Convención de los Derechos de Niños, Niñas y Adolescentes.

2 Este término fue abusivamente utilizado desde posiciones no compartidas por este estudio, de allí el uso de las comillas.

3 Para profundizar la cuestión criminológica estudiada desde diversos campos disciplinares ver capítulo 1 de Marcón (2011).

4 Esta perspectiva conceptual es desarrollada en De Bella (2016).

5 Esta regla refiere a dos de los más importantes objetivos de la justicia de menores. El primero es el fomento del bienestar del/de la menor. Éste es el enfoque principal de los sistemas jurídicos en que los/las menores delincuentes son procesados/as por tribunales de familia o autoridades administrativas, pero también debe hacerse hincapié en el bienestar de los/las menores en los sistemas judiciales que siguen el modelo del tribunal penal, contribuyendo así a evitar las sanciones meramente penales. El segundo objetivo es el principio de la proporcionalidad. Éste es conocido como un instrumento para restringir las sanciones punitivas, y se expresa principalmente mediante la fórmula que reza que el autor/la autora ha de llevarse su merecido según la gravedad del delito. La respuesta a los/las jóvenes delincuentes no sólo deberá basarse en el examen de la gravedad del delito, sino también en sus circunstancias personales. Las circunstancias individuales del delincuente (por ejemplo, su condición social, su situación familiar, el daño causado por el delito u otros factores en que intervengan circunstancias personales) han de influir en la proporcionalidad de la reacción (por ejemplo, teniendo en consideración los esfuerzos del/de la delincuente para indemnizar a la víctima o su buena disposición para comenzar una vida sana y útil).

6 Por el mismo motivo, las respuestas destinadas a asegurar el bienestar del/de la joven delincuente pueden sobrepasar lo necesario y, por consiguiente, infringir los derechos fundamentales del/de lajoven, como ha ocurridoen algunos sistemas de justicia de menores. En este aspecto también corresponde salvaguardar la proporcionalidad de la respuesta en relación con las circunstancias del delincuente y del delito, incluida la víctima.

7 De acuerdo con Eugenio Zaffaroni (1995), el derecho penal de acto concibe al delito como una infracción o lesión jurídica, provocada por un acto humano al que se entiende como la decisión autónoma de una persona. El derecho penal de autor plantea que el delito es signo o síntoma de una inferioridad moral, biológica o psicológica (estado peligroso).

8 Siguiendo la entrevista que le realizara la revista Ornicar en 1977 a Foucault, éste plantea: "El dispositivo es una red. Lo que trato de situar bajo ese nombre es, en primer lugar, un conjunto decididamente heterogéneo, que comprende discursos, instituciones, instalaciones arquitectónicas, decisiones reglamentarias, leyes, medidas administrativas, enunciados científicos, proposiciones filosóficas, morales, filantrópicas; [...] los elementos del dispositivo pertenecen tanto a lo dicho como a lo no dicho. El dispositivo es la red que puede establecerse entre estos elementos. En segundo lugar, lo que querría situar en el dispositivo es precisamente la naturaleza del vínculo que puede existir entre estos elementos heterogéneos. Así pues, ese discurso puede aparecer bien como programa de una institución, bien por el contrario, como un elemento que permite justificar y ocultar una práctica, darle acceso a un campo nuevo de racionalidad. Resumiendo, entre esos elementos, discursivos o no, existe como un juego de los cambios de posición, de las modificaciones de funciones que pueden, estas también, ser muy diferentes [...]. En tercer lugar, por dispositivo entiendo una especie-digamos-de formación que, en un momento histórico dado, tuvo como función mayor la de responder a una urgencia" (Foucault, 1977, como se cita en García Fanlo, 2011, p. 1). Por su parte Agamben (2006) refiere que dispositivo es cualquier cosa que tenga de algún modo la capacidad de capturar, orientar, determinar, interceptar, modelar, controlar y asegurar los gestos, conductas, opiniones y los discursos de los seres vivientes, de modo tal que lo serían no solamente las prisiones, los manicomios, el panóptico, las escuelas, la confesión, las fábricas las disciplinas, sino también la lapicera, la escritura, el cigarrillo, el teléfono celular, las computadoras y por qué no el lenguaje, pero no en sí mismos sino en tanto conforman o forman parte de una red de saber/poder. Un dispositivo no es otra cosa que un mecanismo que produce distintas posiciones de sujetos precisamente por esta disposición en red: un individuo puede ser lugar de múltiples procesos de subjetivación. De acuerdo con García Fanlo (2011, p. 5): "el principal aporte que realiza Agamben al tratamiento de los dispositivos consiste en plantear que no sólo existen por un lado individuos y por el otro dispositivo, sino que existe un tercer elemento que a su juicio resulta fundamental para entender los procesos de subjetivación, individuación y control y es lo que denomina `el cuerpo a cuerpo entre el individuo y los dispositivos. El sujeto sería entonces lo que resulta de la relación entre lo humano y los dispositivos ya que estos existen sólo en la medida en que subjetivan y no hay proceso de subjetivización sin que sus efectos produzcan una identidad y a la vez una sujeción a un poder externo, de modo que cada vez que un individuo asume una identidad, también queda subyugado. Pero siempre, según Agamben, el problema que plantea nuestra actualidad consiste en que los 
dispositivos no sólo subjetivan, sino que también producen procesos de desubjetivación, que son aquellos en los que la creación de un sujeto implica la negación de un sujeto". Asimismo, cabe destacar la referencia que hace Saúl Karsz (2007) respecto a que el Trabajo Social constituye un dispositivo estratégico al ocuparse de cuestiones de orden sociohistórico a partir de asuntos domésticos, incidiendo sobre la historia general al ocuparse de lo que pasa en tal o cual familia.

9 Proyecto presentado por García Méndez en el Congreso Nacional.

\section{Karina De Bella}

karina40debella@gmail.com

Doctorado en Trabajo Social- Facultad de Ciencia Política y RRII, Universidad Nacional de Rosario

Docente Adjunta Cátedra Práctica Profesional I - Escuela de Trabajo Social- Facultad de Ciencia Política y RRII-UNR

\section{Facultad de Ciencia Política y RRII-UNR}

Ciudad Universitaria Rosario, Riobamba 250

Rosario - Santa Fe - Argentina

CPA: 2000

\section{Agradecimientos}

A los/las jóvenes adolescentes que comparten partes de sus vidas conmigo. A la Dra. Alicia González Saibene por incentivar el estudio crítico y la investigación. A mis colegas del fuero de menores. Al Sindicato de Trabajadores Judiciales de la provincia de Santa Fe. A mi familia.

\section{Agencia financiadora}

No se aplica.

Contribuciones de los autores

No se aplica.
Aprobación por Comisión de Ética y consentimiento para participación

No se aplica.

\section{Consentimiento para publicación}

Consentimento da autora.

Conflicto de intereses

No hay conflicto de intereses. 